\title{
A CULTURA DO LÍTIGIO E A ADEQUAÇÃO DOS MEIOS DE SOLUÇÃO DE CONFLITOS SOCIAIS PARA A BUSCA DA PACIFICAÇÃO SOCIAL
}

Ligia Cristina Pereira Schwab ${ }^{1}$ Gilberto Ferreira Marchetti Filho ${ }^{2}$

SCHWAB, L. C. P.; MARCHETTI FILHO, G. F. A cultura do lítigio e a adequação dos meios de solução de conflitos sociais para a busca da pacificação social. Revista de Ciências Jurídicas e Sociais da UNIPAR. Umuarama. v. 23, n. 1, p. 23-54, jan./jun. 2020.

RESUMO: O cenário atual do Brasil é caracterizado por uma cultura excessivamente litigiosa, onde se é passado para o Estado a responsabilidade de resolver os conflitos da sociedade. Em resposta a essa cultura, nos deparamos com uma crise estatal, caracterizada pelo Poder Judiciário abarrotado de demanda, no entanto o poder estatal não tem sido suficiente para sanar tais problemas, ou seja, tem sido ineficaz na busca da pacificação social, ante a isso se faz necessário adequar os meios de solução de conflito, bem como uma mudança de paradigma social, tanto da sociedade, quanto dos operadores do direito em especial, para que haja a aceitação do novo modelo trazido pelo Código de Processo Civil de 2015, e assim promover aos jurisdicionados um acesso à justiça efetivo, justo, eficiente e adequado, bem como, promover a efetiva pacificação social.

PALAVRAS-CHAVE: Cultura do litígio; Conflito; Meios de solução; Pacificação social.

\section{THE CULTURE OF LITIGATION AND THE ADEQUACY OF THE MEANS OF SOLVING SOCIAL CONFLICTS FOR SOCIAL PACIFICATION}

\begin{abstract}
Brazil's current scenario is characterized by an excessively litigious culture, where the responsibility of solving the conflicts of the society is transferred to the state. In response to this culture, the population is faced with a state crisis, characterized by the judicial branch overflowing with demand,

DOI: $10.25110 /$ rcjs.v23i1.2020.8255

${ }^{1}$ Bacharel em Direito pelo Centro Universitário da Grande Dourados - UNIGRAN. Email: ligiaschwab@gmail.com.

${ }^{2}$ Bacharel em Direito e pós-graduado em Direito Civil e Processo Civil pelo Centro Universitário da Grande Dourados - UNIGRAN. Mestre em Processo Civil e Cidadania pela Universidade Paranaense - UNIPAR. Assessor Jurídico do TJMS. Professor de Direito Civil no Centro Universitário da Grande Dourados - UNIGRAN. Email: gilberto.marchetti@unigran.br.
\end{abstract}


yet the state power has not been sufficient to remedy such problems. In other words, it has been ineffective in the search for social pacification. Therefore, it is necessary to adapt the means of conflict resolution as well as providing a change of social paradigm, both of the society in general and of the legal operators in particular, so that there is acceptance of the new model brought by the 2015 Brazilian Code of Civil Procedure, and thus, promote access to effective, fair, efficient, and adequate justice, as well as promoting effective social pacification. KEYWORDS: Litigation culture; Conflict; Means of solution; Social pacification.

\section{LA CULTURA DEL LITIGIO Y LA ADECUACIÓN DE LOS MEDIOS DE SOLUCIÓN DE CONFLICTOS SOCIALES PARA LA BÚSQUEDA DE LA PACIFICACIÓN SOCIAL}

RESUMEN: El escenario actual de Brasil se caracteriza por una cultura excesivamente litigiosa, donde la responsabilidad de resolver los conflictos de la sociedad se transfiere al estado. En respuesta a esta cultura, nos enfrentamos a una crisis estatal, caracterizada por el poder judicial cargado de demanda, pero el poder estatal no ha sido suficiente para remediar tales problemas, es decir, ha sido ineficaz en la búsqueda de la pacificación social. Es necesario adaptar los medios de resolución de conflictos, así como cambios en el paradigma social, tanto de la sociedad como de los operadores legales en particular, para que se acepte el nuevo modelo presentado por el Código de Procedimiento Civil de 2015, y promover el acceso efectivo, justo, eficiente y adecuado a la justicia para los jurisdiccionales, así como promover la pacificación social efectiva.

PALABRAS CLAVE: Cultura del litigio; Conflicto; Medios de solución; Pacificación social.

\section{INTRODUÇÃO}

Com a evolução da sociedade brasileira e dos fundamentos que a regem, foi necessário repensar a forma de visualização das resoluções dos conflitos. Uma vez que os métodos que se tinha eram extremamente litigiosos e repressivos, não condizendo com o que a evolução do direito espera, pois esta é regida por princípios constitucionais que buscam dar efetividade a dignidade da pessoa humana.

Desta forma, com a promulgação da Lei Federal n. 13.105, de 16 de março de 2015 - Código de Processo Civil tentou-se romper com modelo de tratamento que era dado aos conflitos, pois este trouxe um novo padrão de visualização do processo, não se limitando apenas a repressão, mas também a 
prevenção, plasmado na ideia de adequação dos meios de solução de conflito, e na pacificação social, para a partir disso promover um acesso à justiça efetivo, justo, eficiente e adequado.

Assim o presente trabalho tem o fim de estudar e tentar compreender a evolução de tal ideia, suas raízes, abordando o surgimento dos conflitos, os meios de solução, a situação critica em que o Poder Judiciário se encontra e as consequências disto, bem como as soluções, as portas que o Código de Processo Civil abre para se alcançar a efetivação de direitos de forma adequada e promover a pacificação social.

\section{O CONFLITO}

O homem em sua essência é um ser social, desde que o mundo é mundo o homem demonstra a necessidade que possui de viver em sociedade, de estar em contato com outros seres semelhantes a si, gerando assim grupos diversos, onde cada um deles tem seu próprio modo de agir e pensar, ou seja, o homem não consegue viver sozinho, por conta própria.

Assim, "a sociabilidade é a propensão do homem para viver junto com os outros e comunicar-se com eles, torná-los participantes das próprias experiências e dos próprios desejos, conviver com eles as mesmas emoções e os mesmos bens" (MONDIN, 1980, p. 159).

Esse convívio começa no seio familiar, e com o passar do tempo o grupo social do indivíduo é alargado com base nos seus interesses, cultura e local. Desta forma, foi necessário desenvolver regras para regular as relações pessoais, pois a ausência dessas importaria em um caos, porque cada ser, apesar de possuir características semelhantes (leia-se viver em sociedade), pensam de formas diferentes.

Sociabilidade e politicidade são, então, dois aspectos correlativos de único fenômeno: o homem é sociável e, por isso, tende a entrar em contacto com os seus semelhantes e a formar com eles certas associações estáveis; porém, começando a fazer parte de grupos organizados, torna-se um ser político, ou seja, membro de uma polis, de uma cidade, de um estado, e, como membro de tal organismo, adquire certos direitos e assume certos deveres. (MONDIN, 1980, p. 159)

Diante do fato de serem seres semelhantes, que pensam de formas diferentes, há divergências de ideias, entre os grupos e dentro deles, que geram conflitos. Assim o conflito é entendido como um fato social, decorrente da 
divergência de interesses pessoais.

O conflito resulta da percepção da divergência de interesses, é um fato pessoal, psicológico e social que deságua no direito apenas por opção política da organização social, variando essa intervenção do Estado conforme variam todos os demais fatores históricos, políticos e geográficos. O conflito que envolve empresas é, ainda, um fenômeno econômico, que pode gerar consequências mais amplas. Quando se trata de interesses que não podem ser individualizados (metaindividuais), a importância social do conflito é ainda maior. Os conflitos implicam em lutas entre duas ou mais pessoas acerca de valores, posição e recursos. (CALMON, 2015, p. 16)

Entendido que o conflito é a divergência de interesses, e que esse resulta na quebra do convívio social, é necessário "entender os meios pelos quais tais conflitos podem ser solucionados, a fim de restabelecer o equilíbrio das relações sociais e a pacificação da sociedade" (FILHO, 2018, p. 37).

\section{OS MEIOS DE SOLUÇÃO DE CONFLITO}

Conforme já explicado é natural a ocorrência de conflitos dentro da sociedade, diante de tal situação se fez necessário desenvolver técnicas para sanar as controvérsias existentes. "Por vezes, essa solução é buscada à margem do Direito, por atuação das próprias partes; outras vezes, essa solução se impõe pela violência; e, em outras, a solução é colocada por um terceiro" (FILHO, 2018, p. 38).

Assim, identificamos três técnicas de soluções para os conflitos, as quais são a autotutela, autocomposição e heterocomposição, que passamos a analisar individualmente.

\subsection{A Autotutela}

A autotutela é caracterizada pela justiça feita pelas próprias mãos, ou seja, o indivíduo soluciona o conflito com o uso de sua força, nesse sentido Tartuce (2016, p. 19) explica que "pela autotutela (ou autodefesa), o indivíduo resolve o conflito por sua própria força, agindo por si próprio para obter uma posição de vantagem em relação à situação desejada".

Esse método não tem muita aceitação, pois pressupõe o uso da violência "É caracterizada pelo uso ou ameaça de uso da força, perspicácia ou esperteza" (CALMON, 2015, p. 23). Calmon (2015, p. 24-25) explica que esse instituto só 
teve aplicabilidade nas sociedades primitivas "aplicada de forma generalizada somente em sociedades primitivas, pois conduz ao descontrole social e à prevalência da violência".

Tal aplicabilidade se dá ao fato que nas sociedades primitivas, não se tinha a figura do Estado regendo as relações particulares da sociedade, nessa perspectiva:

[...] não havia nem um órgão estatal soberano e com autoridade para cumprir e fazer cumprir a lei, muito menos leis para assegurar o direito, assim tais leis passaram a existir na sua forma primitiva, 'legalizaram' a autotutela pelo regime da vingança privada, como no Código de Hamurabi, que tinha por base a Lei de Talião [...]. (FILHO, 2018, p. 46)

Assim, este instituto não tem aplicabilidade nas relações modernas, porque a sua aplicação implica na ocorrência de novos conflitos e não na solução dos mesmos.

A autotutela constitui forma inadequada e imprópria de encerrar o conflito. Em geral, reproduzirá resultados que não correspondem à pauta de conduta aceita e aplicada à relações sociais não litigiosas. A autotutela provoca o risco latente de estimular e multiplicar os conflitos, em vez de solucioná-los definitiva e eficazmente. Por esse motivo, a marcha da civilização exigiu sua contenção, tendendo à extinção. (ASSIS, 2016, v. 1, p. 57-58)

No entanto, aborda algumas exceções. Em situações de urgência é possível visualizar a sua aplicabilidade. Cita-se rol exemplificativo trazido por Filho (2018, p. 48):

Dentre elas, cita-se, a título exemplificativo, a legitima defesa e o estado de necessidade no direito penal; o desforço imediato na posse, a legitima defesa, o estado de necessidade, o direito de retenção de benfeitorias, o penhor legal no direito civil; o princípio da autoexecutividade dos atos administrativos no direito administrativo; as greves, a rescisão indireta e algumas penalidades aplicadas aos empregados no direito do trabalho.

Logo, na atualidade, a autotutela, a despeito de presente no ordenamento 
jurídico, deve ser vista como exceção e aplicável apenas em casos extremamente excepcionais.

\subsection{A Autocomposição}

A autocomposição tem como principal característica a resolução dos conflitos pelos próprios litigantes, por essa técnica uma das partes envolvidas no litígio, ou ambas, despojam-se de seu direito ou de parte dele, para dar fim à controvérsia existente entre eles. Assim a autocomposição "se dá quando o envolvido, em atividade de disponibilidade, consente no sacrifício de seu próprio interesse, unilateral ou bilateralmente, total ou parcialmente" (CALMON, 2015, p. 24-25).

Os meios autocompositivos são considerados aqueles onde as próprias partes põem termo ao conflito. Tem-se aqui uma solução não-adversarial, porquanto construída pelas pessoas envolvidas no conflito de interesses. Caracteriza-se, pois, pelo fato do conflito ser solvido de maneira unilateral ou bilateral pelas partes, com ou sem auxílio de um terceiro alheio ao conflito. (FILHO, 2018, p. 50)

Filho (2018, p. 55) ainda esclarece que a autocomposição pode se manifestar de três formas: "1) unilateral, pela renúncia e desistência, ou bilateral, pela transação; 2) espontânea, quando obtida pelas próprias partes, ou induzida, quando há atuação de um terceiro (conciliador ou mediador); 3) extra ou endoprocessual, considerando o momento em que ela ocorre", ou seja, se ocorrer antes ou depois de formada a relação processual.

As principais formas de autocomposição são a conciliação e a mediação. São institutos semelhantes, pois ambos pressupõem a presença de um terceiro intervindo no conflito de forma imparcial para ajudar as partes envolvidas a entrarem em consenso.

Pode ocorrer que as partes não consigam, sozinhas, comunicar-se de forma eficiente e entabular uma resposta conjunta para a composição da controvérsia. Afinal, a deterioração da relação entre os indivíduos pode acarretar graves problemas de contato e comunicação. Nessas situações, pode ser recomendável que um terceiro auxilie as partes a alcançar uma posição mais favorável na situação controvertida, por meio da mediação ou da conciliação. (TARTUCE, 2016, p. 47)

A conciliação é a forma de autocomposição pelo qual há a intervenção 
de um terceiro imparcial chamado de conciliador, que tem por função ajudar as partes a entrarem em consenso, pondo fim a controvérsia.

Por tal técnica de autocomposição, um profissional imparcial intervém para, mediante atividades de escuta e investigação, auxiliar os contendores a celebrar um acordo, se necessário expondo vantagens e desvantagens em suas posições e propondo saídas alternativas para a controvérsia, sem, todavia, forçar a realização do pacto. (TARTUCE, 2016, p. 48)

O conciliador pode apresentar propostas de soluções, no entanto não pode decidir pelas partes, "o conciliador, de forma mais pontual, busca a obtenção de acordos, inclusive sugerindo maneiras de alcançá-lo e extinguir o litígio porventura já instalado, formulando possíveis propostas de composição" (TARTUCE, 2016, p. 47).

Este instituto tem por característica ser mais célere que a mediação, pois pode ser desenvolvido em um único ato, e o enfoque é objetivo, pois é indicado para casos que não tenham uma relação anterior entre os litigantes.

Esse entendimento pode ser extraído do Código de Processo Civil de 2015 , o qual estabelece em seu art. $165, \S 2^{\circ}$, que "o conciliador, que atuará preferencialmente nos casos em que não houver vínculo anterior entre as partes, poderá sugerir soluções para o litígio, sendo vedada a utilização de qualquer tipo de constrangimento ou intimidação para que as partes conciliem".

Por sua vez, a mediação trata-se de forma autocompositiva de solução de conflitos, regida pela Lei ${ }^{\circ} 13.140 / 2015$. Este instituto é bem semelhante a conciliação, pois nessa forma de autocomposição, também há a intervenção de um terceiro imparcial, auxiliando as partes, aqui chamado de mediador.

Mediação é o meio consensual de abordagem de controvérsias em que uma pessoa isenta e devidamente capacitada atua tecnicamente para facilitar a comunicação entre as pessoas para propiciar que elas possam, a partir da restauração do diálogo, encontrar formas proveitosas de lidar com as disputas. (TARTUCE, 2016, p. 52)

O mediador tem a função de restabelecer o dialogo entre as partes, para que estas por conta própria, consigam achar uma solução adequada para por fim a controvérsia.

O mediador não induz propriamente as pessoas a um acordo, mas contribui para o restabelecimento da 
comunicação, de modo que elas gerem novas formas de relacionamento e equacionamento de controvérsias. Sua atuação ocorre no sentindo de provocar a reflexão para que os próprios indivíduos encontrem saídas para o conflito. (TARTUCE, 2016, p. 47)

A mediação se mostra mais complexa que a conciliação, pois "geralmente conta com diversas sessões entre os envolvidos; por meio de intervenções apropriadas, o mediador contribui para o alívio das resistências de modo que estes protagonizem saídas consensuais para o impasse". (TARTUCE, 2016, p. 55)

Esse entendimento também pode ser vislumbrado, através da leitura do Código de Processo Civil de 2015, no seu art. 165, § $3^{\circ}$, dispondo que "O mediador, que atuará preferencialmente nos casos em que houver vínculo anterior entre as partes, auxiliará aos interessados a compreender as questões e os interesses em conflito, [...]".

\subsection{A Heterocomposição}

A heterocomposição é a técnica pela qual um terceiro põe fim ao conflito. Filho diz que "a heterocomposição é o meio de solução no qual se tem a participação efetiva de um terceiro imparcial” (2018, p. 68). Assim, é imprescindível que um terceiro imparcial, ou seja, que não tem envolvimento com o caso, e tome a decisão pelas partes.

Diante disso, temos que os métodos heterocompositivos podem se manifestar basicamente de duas formas: "a arbitral, em que o terceiro, de confiança das partes, é por elas escolhido para decidir o impasse; e a jurisdicional, em que uma das partes acessa o Poder Judiciário para obter uma decisão proferida por uma autoridade estatal investida de poder coercitivo" (TARTUCE, 2016, p. 56).

A arbitragem é a forma heterocompositiva de solução de conflitos, regida pela Lei n. 9.307/1996 que foi alterada pela Lei n. 13.129/2015. Tal procedimento compreende na escolha de uma terceira pessoa de confiança das partes para solucionar a controvérsia, sem a participação do poder judiciário.

Assim a "arbitragem consiste em um antigo método de composição das controvérsias consistente na escolha das partes de uma terceira pessoa para definir o destino da controvérsia" (TARTUCE, 2016, p. 56).

Essa terceira pessoa intitulada de arbitro, mesmo que de confiança das partes, é imparcial. "Na arbitragem, a decisão sobre o conflito será proferida por uma pessoa de confiança, mas equidistante em relação às partes; o árbitro, embora desprovido de poder estatal [...], profere decisão com força vinculativa" (TARTUCE, 2016, p. 57). 
Em nosso sistema jurídico, o objeto da controvérsia submetida à arbitragem, nos termos do art.1. ${ }^{\circ}$ da Lei n. 9.307/1996, deve corresponder a direitos patrimoniais disponíveis, tendo sido eleita a via arbitral por pessoas capazes de contratar. Em tal hipótese, dispõe o art. 18 da Lei que o árbitro validamente escolhido pelas partes é o juiz de fato e de direito da controvérsia, não ficando sua decisão sujeita a recurso ou homologação perante o Poder Judiciário. (TARTUCE, 2016, p. 57)

De outro norte, no processo judicial as partes em conflito, levam a situação ao poder estatal, e espera que este, em contrapartida, dê uma resposta, estabelecendo quem tem direito ou não através de uma sentença. "Tal mister é realizado por meio da jurisdição, pela qual o Estado, substituindo-se às partes, diz a norma aplicável ao caso concreto com o poder imperativo de impor o seu comando" (TARTUCE, 2016, p. 62).

Desta forma, "a solução judicial da controvérsia constitui modalidade de heterocomposição potencialmente apta a propiciar a resposta ao conflito de interesses que não pode ser debelado pelos próprios envolvidos na relação litigiosa e que precisa de um elemento coercitivo para sua realização" (TARTUCE, 2016, p. 62).

Assim, o terceiro imparcial neste caso, é o próprio Estado exercendo a jurisdição, que por sua vez, é o poder do estado de fazer incidir a norma ao caso concreto, promovendo a pacificação dos conflitos, através de um conjunto de atos, chamado de processo.

Porém, o que deveria de certa forma ser rápido e otimizado, tornouse moroso e pouco efetivo, diante da rigidez processual e da litigiosidade, fato resultando assim na defasagem do objetivo maior da lei de dar a devida prestação jurisdicional a quem dela necessita.

\section{AADEQUAÇÃO DOS MEIOS DE SOLUÇÕES DE CONFLITO PARAA BUSCA DA PACIFICAÇÃO SOCIAL}

Quando fala-se em pacificação social logo se imagina uma sociedade perfeita, onde não há conflitos nem qualquer tipo de desentendimentos, porém tal pensamento caracteriza uma realidade impossível, já que o conflito é algo inerente ao ser humano, visto que o mesmo nasceu para viver em comunidade, e a partir do momento que relaciona-se com seu co-igual é natural que haja a colisão de ideias.

Pensando nisto, faz-se necessário buscar meios para que tais conflitos sejam solucionados, sendo que as formas utilizadas devem ser eficientes, justas, 
eficazes e adequadas, para que assim haja a efetiva pacificação social tão almejada por todos os componentes da sociedade.

Desta forma, há que ser utilizado de maneira pratica todos os mecanismos propostos pelo Estado, com o objetivo de resolver as demandas geradas a partir do desentendimento entre comuns, pois, caso não haja esta utilização, o resultado será a desordem catastrófica que tem como resultado uma séria crise Estatal, haja vista que desta maneira a tão almejada pacificação social torna-se algo quase utópico, mas que ainda pode ser alcançada.

\subsection{A crise estatal: Dados do CNJ}

Abordado de forma singela o conflito e os meios de solução, necessário se faz tratar a situação jurídica vigente no Brasil. Como já explicado o surgimento de conflitos é algo natural, intrínseco a sociedade.

Fomos educados a passar para o Estado a responsabilidade de resolver tais controvérsias, "no Brasil desenvolveu-se, desde sempre, uma cultura segundo a qual os conflitos deveriam ser solucionados por meio da atuação do Poder Judiciário. Houve, por assim dizer, uma judicialização dos conflitos" (CÂMARA, 2014, p. 40).

Nesse mesmo sentindo Calmon explica que no Brasil a sociedade tem "uma cultura de conflitos, na qual não somente se verifica um enorme e interminável quantidade de conflitos, como, igualmente, o hábito predominante de atribuir ao Estado a responsabilidade de proporcionar sua solução" (CALMON, 2015, p. 19).

No entanto em uma análise do cenário atual do judiciário, observa-se que a prestação jurisdicional não tem sido suficiente para sanar tais problemas, podemos assim dizer que estamos diante de uma crise estatal.

Quando se fala em crise estatal, não se limita apenas ao Poder Judiciário, Filho (2018, p. 111) explica que "ao judiciário caberia recepcionar, por definição, as crises propriamente jurídicas, ficando as demais, ocorrentes em outros campos [...] a cargo dos outros Poderes".

Todavia, "o que se tem na prática é que o Judiciário acaba por ter que lidar com questões que vão muito além de recepcionar os conflitos sociais e dar-lhes solução jurídica" (FILHO, 2018, p. 111), ou seja, isso demonstra que tal situação abarcar todos os Três Poderes (legislativo, executivo e judiciário). “Assim, 'será de todo inoperante qualquer tentativa de solução parcial abrangendo apenas o Judiciário, dado que sua crise ocorre [...] em consequência de uma infecção externa', que se generalizou a partir da década de 90 e mostrou suas feridas exatamente no Judiciário" (FILHO, 2018, p. 111).

Dessa forma, a crise estatal "pode ser analisada sob diversos aspectos, tanto no tocante às leis, quanto à estrutura e à quantidade de processos ingressados 
e que acabaram por encontrar um sistema despreparado para apresentar a tutela jurisdicional que o Estado Constitucional exige" (FILHO, 2018, p. 110).

Tal crise pode ser demonstrada com base em pesquisas recentes, realizadas pelo Conselho Nacional de Justiça - CNJ, Justiça em Números 2017 e 2018, que tiveram como base o ano de 2016 e 2017 respectivamente.

A pesquisa nos mostra que no ano de 2016, foram ingressados 29,4 milhões de processos e baixados a mesma quantidade, no entanto restaram em tramitação 79,7 milhões de processo (BRASIL, 2017, p. 67), já no ano de 2017, foi finalizado com 80,1 milhões de processos, sendo 29,1 milhões a quantidade de processos novos e 31 milhões de processos baixados (BRASIL, 2018, p. 73).

O CNJ nos mostra ainda que a maior concentração de processos se encontra na Justiça Estadual, em um percentual de aproximadamente $79 \%$ em ambos os anos. Ainda um dado interessante apontado pela pesquisa de 2018, é que mesmo que não houvesse processos novos, e mantivessem a produção dos servidores e magistrados seria necessário mais de 2 anos e meio para zerar o acervo de processos em tramitação (BRASIL, 2018, p. 74).

Podemos atribuir como um dos fatores dessa crise, além da cultura de litígio arraigada na sociedade, o modelo processual que se era empregado até a entrada em vigor do código de processo civil de 2015.

\subsection{Um breve comparativo entre o modelo processual do Código de Processo Civil de 1973 e de 2015}

Um dos fatores responsáveis por essa crise pode ser imputado ao modelo processual do Código de Processo Civil de 1973, o qual "teve sua importância para a evolução do pensamento científico processual brasileiro da época, principalmente quando comparado com o Código de 1939 [...]" (FILHO, 2018, p. 99-100).

No entanto, este Código tinha como característica ser "individualista, patrimonialista, impregnado pela ideologia de liberdade e da segurança jurídica na visão do século XIX" (FILHO, 2018, p. 100). O que acarreta no "seu descompasso com a evolução da ciência processual do meio do século XX" (FILHO, 2018, p. 101), pois "foi pensado e feito na adequação de uma sociedade do Século XIX, para tutelar o que havia de direito material no Código Civil de 1916" (FILHO, 2018, p. 109).

Diante dessas qualidades e tendo em vista sua vocação repressiva, o Código de Buzaid também se caracterizava pela litigiosidade, ou seja, retratava o que se chama de cultura do litígio. Com efeito, não havia a preocupação com a evitação do conflito ou com as longas disputas judiciais. Não se tinha meios de prevenção, com tutelas 
de abstenção. O que se buscava era repressão, visando apenas a reparação do dano, o que, junto com seu rigorismo técnico e sistemática recursal, estimulava o litígio e demandas intermináveis. (FILHO, 2018, p. 109)

Tem-se desta forma a conclusão de que o Código de Processo Civil de 1973 era excessivamente repressivo, visando única e exclusivamente o litígio como resolução de conflitos entre particulares, o que funcionou por certo período de tempo, levando-se em conta que o direito positivado regulamenta o comportamento social.

Porém tal método, com o passar do tempo, tornou-se defasado, e resultou no acúmulo processual em grande parte dos tribunais do país, o que tem refletido ainda hoje. Então, levando-se em conta tal motivo e a evolução da sociedade, se iniciou a elaboração de um novo código, que objetivava regulamentar a mudança social, buscando novos métodos para a resolução de conflitos, agora com um caráter mais preventivo do que repressivo.

Desta forma, o Código de Processo Civil de 2015 trouxe um novo padrão, pois efetiva em seu texto a prevenção, baseado nos princípios constitucionais, dentre os quais destaca-se o princípio da dignidade da pessoa humana, que ganhou maior enfoque quando da elaboração e promulgação da Constituição Federal de 1988.

Assim, explica Filho acerca dos objetivos do novo Codex:

[...] busca-se compreender o Código de Processo Civil de 2015 como ferramenta hábil para o aprimoramento do acesso à justiça efetiva, justa, eficiente e adequada na solução dos conflitos, numa visão de processo como instrumento da garantia dos direitos fundamentais e com objetivo de proporcionar a pacificação social, o escopo social finalístico de todo processo. (FILHO, 2018, p. 138)

Ainda citando Filho (2018, p. 137):

Não é um Código perfeito, como admitido pela própria comissão organizadora. Todavia tem por mérito ressistematizar o sistema processual civil brasileiro com o quê de mais moderno se tem hoje, tanto nas suas bases, com técnicas legislativas modernas - princípios, conceitos indeterminados e cláusulas gerais -, quanto no alinhamento do seu texto e estrutura com a Constituição Federal, estabelecendo um processo justo e voltado não para o estimulo da litigiosidade, mas sim para um tutela 
dos direitos, preventiva e repressiva.

Aduz-se então, que quando da entrada em vigor do Código de Processo Civil de 2015, houve a tentativa de ruptura da cultura do litígio, que ainda caminha a passos lentos, mas que com o tempo se tornará efetiva.

Portanto, inicia-se um novo entendimento acerca da resolução de conflitos, sendo preferível os meios autocompositivos, ainda que pouco estimulados, pois ainda hoje alguns operadores do direito possuem a mentalidade de que a maneira mais eficaz para a pacificação social é o litígio, quando na verdade este método encontra-se ultrapassado e combatido tanto pela Constituição federal, quando pelo Código de Processo Civil.

Desta forma, em linhas conclusivas de raciocínio podemos dizer que o Código de Processo Civil de 2015 trouxe um novo paradigma, ou seja, um novo modelo processual, com enfoque na prevenção, resoluções adequadas e céleres.

No entanto ainda analisando a crise estatal vigente, podemos dizer que um dos efeitos desta crise é o cerceamento do devido acesso à justiça, pois tal prestação jurisdicional, como já dito, é excessivamente litigiosa e morosa, não atendendo a Constituição Federal de 1988 que "ampliou em largos passos o acesso à justiça, ao atribuir a ele o status de garantia fundamental" (FILHO, 2018, p. 111).

\subsection{O devido acesso à justiça}

Como mencionado uma das consequências da crise estatal é o cerceamento do devido acesso a justiça, tema este que passamos analisar de forma um pouca mais abrangente, diante da sua complexidade e magnitude.

Tal 'expressão 'acesso à Justiça' é reconhecidamente de difícil definição, mas serve para determinar duas finalidades básicas do sistema jurídico - o sistema a pelo qual as pessoas podem reivindicar seus direitos e/ou resolver seus litígios sob os auspícios do Estado" (CAPPELLETTI; GARTH, 1988, p. 8).

Assim quando se fala em devido acesso à justiça, logo se cria a imagem de um indivíduo propondo uma demanda judicial, deste modo o "direito ao acesso à proteção judicial significava essencialmente o direito formal do indivíduo agravado de propor ou contestar uma ação" (CAPPELLETTI; GARTH, 1988, p. 9).

Esta era a visão que se tinha, no entanto com a evolução do direito e da sociedade o devido acesso à justiça passa a ser tratado como uma garantia individual, um direito fundamental. Filho (2018, p. 172) explica que o "desenvolvimento da sociedade e do conflito, na sua natureza e complexidade, exigiu uma mudança radical de pensamento, principalmente com a evolução da noção de direitos humanos em nível internacional e dos direitos fundamentais no 
plano interno".

Nesse campo, o acesso à justiça deixa de ser contemplado apenas como o direito de ingressar em juízo. Ganha contornos materiais, sendo tratado, a partir de então, como um direito fundamental para garantir a efetividade dos direitos sociais e individuais da pessoa que surgiam na mudança da sociedade e do pensamento jurídico. (FILHO, 2018, p. 173)

Assim o acesso à justiça pode ser "encarado como requisito fundamental - o mais básico dos direitos humanos - de um sistema jurídico moderno e igualitário que pretenda garantir, e não apenas proclamar os direitos de todos" (CAPPELLETTI; GARTH, 1988, p. 12).

[...] o acesso à justiça dentro da ideia de democratização do direito como um todo, mas principalmente o processual, ganha contornos muito mais significativos do que apenas a garantia de se bater às portas do Judiciário e de se ter o direito a uma sentença de mérito que "põe fim ao conflito", ao menos tecnicamente falando. (FILHO, 2018, p. 175)

Deste modo, "o sistema deve oferecer aos conflitos uma solução que promova sua pacificação, ou seja, uma solução adequada, com efetividade, justiça e eficiência" (FILHO, 2018, p. 175). Nesse sentindo, é "indispensável aprimorar internamente a ordem processual, habilitando-a a oferecer resultados úteis e satisfatórios aos que se valem do processo" (DINAMARCO, 2016, v. 1, p. 205).

Seguindo essa linha de raciocínio podemos dizer então, que não basta ter o direito de ingressar com uma demanda judicial, de ter sua petição analisado pelo Estado-juiz, mas sim que essa atividade estatal deve primar pela efetividade, justiça, eficiência e adequação, ou seja, ao acesso à justiça material, requisitos esses que passamos a analisar adiante.

Quando se fala em um acesso à justiça efetivo, existe certa dificuldade de em conceituá-lo, Cappelletti e Garth (1988, p. 15) nos explicam que "o conceito de 'efetividade' é, por si só, algo vago. A efetividade perfeita, no contexto de um dado direito substantivo, poderia ser expressa como a completa "igualdade de armas"".

A igualdade de armas deve ser entendida pela "situação na qual as partes estão posicionadas de tal forma no processo que ambas têm os mesmos instrumentos, dentro de um equilíbrio - como uma balança de pesos -, para 
exposição dos fatos e fundamentos jurídicos, com suas respectivas provas" (FILHO, 2018, p. 117), como de fato se espera que o Poder Judiciário seja.

Trata-se por assim dizer de um acesso material, está ligado aos meios colocados a disposição das partes, com o fim de garantir "que a conclusão final depende apenas dos méritos jurídicos relativos das partes antagônicas sem relação com diferença que sejam estranhas ao Direito e que, no entanto afetam a afirmação e reivindicação dos direitos" (CAPPELLETTI, GARTH, 1988, p. 15).

Deste modo, "o direito ao acesso efetivo tem sido progressivamente reconhecido como sendo de importância capital entre os novos direitos individuais e sociais, uma vez que a titularidade de direitos é destituída de sentindo, na ausência de mecanismos para sua efetiva reinvidicação" (CAPPELLETTI, GARTH, 1988, p. 11-12).

Nesse viés, passamos a analisar o que é considerado um acesso à justiça justa, "quando se fala em acesso à ordem jurídica justa, tem-se a referência de que o Estado deve promover um acesso à justiça que considere a natureza e complexidade do conflito, as diferenças sociais e culturais da sociedade brasileira" (FILHO, 2018, p. 178),

Podemos dizer, assim, que é ter acesso ao Poder Judiciário com pessoas aptas a perceber a realidade social vigente e as suas implicações.

[...] não se admite no processo constitucional-democrático, com uma visão humanista, a figura do juiz do século XIX e boa parte do século XX, enclausurado em seu gabinete, afastado da realidade da sociedade moderna e da complexidade dos conflitos que chegam até ele. É preciso considerar as pessoas envolvidas, em sua individualidade, cada qual com suas necessidades e particularidades e que apresentam ao Judiciário conflitos que, por vezes, representam tudo que têm. (FILHO, 2018, p. 179)

No entanto tal conceito não se limita a isso. Dinamarco (2016, v.1, p. 206) acrescenta que ter acesso a uma ordem jurídica justa, equivale a uma justiça substancial. Ainda esclarece que não se tem "justiça substancial quem não consegue sequer o exame de suas pretensões pelo Poder Judiciário e também quem recebe soluções atrasadas ou mal formuladas para suas pretensões, ou soluções que não lhe melhorem efetivamente a vida em relação ao bem pretendido" (2016, v. 1, 206).

Acesso à justiça não equivale a mero ingresso em juízo. A própria garantia constitucional da ação seria algo inoperante e muito pobre se resumisse a assegurar que 
as pretensões das pessoas cheguem ao processo, sem garantir-lhes também um tratamento adequado. É preciso que as pretensões apresentadas aos juízes cheguem efetivamente ao julgamento de fundo, sem a exacerbação de fatores capazes de truncar o prosseguimento do processo, mas também o próprio sistema processual seria estéril e inoperante enquanto se resolvesse numa técnica de atendimento ao direito de ação, sem preocupações com os resultados exteriores. (DINAMARCO, 2016, v. 1, 206)

Assim, para o "exame substancial da pretensão, é indispensável que as partes sejam tratadas com igualdade e admitidas a participar, não se omitindo da participação também o próprio juiz, de quem é a responsabilidade principal pela condução do processo e correto julgamento da causa" (DINAMARCO, 2016, v. 1, 206).

Portanto, não basta que "o processo produza decisões intrinsecamente justas e bem postas mas tardias ou não traduzidas em resultados práticos desejáveis; nem sendo desejável uma tutela jurisdicional efetiva e rápida, quando injusta" (DINAMARCO, 2016, v. 1, p. 205), dessa forma para se alcançar "a plenitude do acesso à justiça importa remover os males resistentes à universalização da tutela jurisdicional e aperfeiçoar internamente o sistema, para que seja mais rápido e mais capaz de oferecer soluções justas e efetivas" (DINAMARCO, 2016, v. 1, 206), nesse viés, adentramos ao campo da eficiência.

Em seu entendimento, Filho (2018, p. 180) explica que a eficiência "mede a relação entre os meios empregados e os resultados alcançados. Quanto maior o rendimento de produção mais eficiente será a atividade desenvolvida".

Logo, temos que considerar que a "satisfação no seio da eficiência só é atingida se a tutela chegar ao jurisdicionado em tempo hábil e com a qualidade necessária" (FILHO, 2018, p. 180-181).

Assim, a "análise da eficiência precisa partir da premissa de que o objetivo do processo civil constitucional é a resolução de disputas por meio de decisões justas" (FILHO, 2018, p. 181), e que "além da importância do elemento tempo para se chegar à resolução da disputa, é preciso também considerar os fatores relativos à qualidade e ao conteúdo da decisão final" (FILHO, 2018, p. 181).

Diante disso, para ser justa, uma decisão deve ter por base uma apresentação adequada, completa e justa dos aspectos legais de seu caso por ambas as partes, bem como uma decisão precisa, completa, justa e possivelmente verdadeira sobre os fatos. Sob esse prisma, o acesso à justiça é eficiente quando é razoavelmente rápido, 
mas também quando está estruturalmente orientado para alcançar decisões totalmente informadas, precisas, confiáveis e justas. (FILHO, 2018, p. 181)

No mais, o devido acesso à justiça eficiente é desenvolvido em dois aspectos: quantitativo e qualitativo. A eficiência no seu aspecto quantitativo analisa a duração razoável do processo, estando formalmente previsto na Constituição Federal em seu art. $5^{\circ}$, LXXVIII, tendo caráter de garantia fundamental, "a todos, no âmbito judicial e administrativo, são assegurados a razoável duração do processo e os meios que garantam a celeridade de sua tramitação" (BRASIL, 1988).

Deste modo quando falamos em "razoável duração do processo, quer se referir a um processo cujo fim se apresente em tempo que possa efetivamente ser eficiente para resolver a lesão ou ameaça de lesão ao direito que a pessoa reclama socorro ao Judiciário" (FILHO, 2018, p. 182), como já explicado, "uma decisão tecnicamente efetiva, mas tardia, está desprovida de eficiência, porquanto o que se pretendia proteger já não existe mais - pelo menos não no estado em que se deseja a proteção" (FILHO, 2018, p. 183).

Passando então ao aspecto qualitativo, que corresponde à colaboração entre o juiz e as demais partes envolvidas no processo, com o emprego de técnicas adequadas de aplicação do direito, Filho ao citar Cunha explica que a justiça eficiente de qualidade condiz com a gestão do processo e com o princípio da adequação (2018, p. 185 apud 2016, p. 378).

Sendo assim, é necessário que o juiz molde o processo a cada caso concreto, libertando-se da rigidez processual, para alcançar resultados eficientes, como bem preceitua o Código de Processo Civil em seu art. 139, inciso IV, que concerne ao juiz "dilatar os prazos processuais e alterar a ordem de produção dos meios de prova, adequando-os às necessidades do conflito de modo a conferir maior efetividade à tutela do direito" (BRASIL, 2015).

Retratando assim "o acesso à justiça no campo formal, como direito de ingressar em juízo, e também o acesso à justiça material, isto é, efetiva, justa e eficiente - tanto quantitativamente quanto qualitativamente" (FILHO, 2018, p. 186), devendo haver uma paridade de armas, percepção da realidade social, duração razoável do processo e a gestão adequada do processo.

Chegamos assim, ao último requisito que o acesso à justiça no seu conceito moderno exige, sendo, a adequação, que irá aborda a instrumentalidade processo, como forma de garantia de tutela adequada de direitos, "o acesso à justiça e o direito de ação manifestam-se "não apenas através da demanda, mas também ao longo do desenvolvimento de todo o procedimento, [...]" (MEDINA, 2016, p. 136-137). 
Em verdade, o acesso à justiça, hoje, mostra mais uma face que é de extrema importância para atender ao seu escopo social: ele deve ser adequado para promover a pacificação social! A efetividade, ordem jurídica justa e eficiência não serão obtidas se o instrumento utilizado para tal e a solução apresentada não forem adequados. (FILHO, 2018, p. 187)

Trata-se assim o acesso à justiça adequado de um compilado de múltiplos fatores, que buscam a efetivação de direitos, e a pacificação social, sendo alguns destes:

(i) a organização judiciária adequada à realidade do país, com sua modernização e realização de pesquisa permanente para o conhecimento dessa realidade e dos conflitos que nela ocorrem; (ii) a organização de serviços voltados ao tratamento adequado das controvérsias, inclusive com a utilização de mecanismos consensuais de solução de conflitos, como a mediação e a conciliação; (iii) a adequação dos instrumentos processuais à efetiva tutela dos direitos individuais e coletivos dos jurisdicionados; (iv) a organização adequada dos serviços de assistência jurídica integral, que propicie não somente o acesso aos órgãos judiciários, como também orientação e informação jurídica; (v) a formação adequada dos juízes e seu permanente aperfeiçoamento; (vi) a remoção dos diferentes obstáculos (econômico, social, cultural, e de outras espécies) que se anteponham ao acesso à ordem jurídica justa; (vii) e pesquisa interdisciplinar permanente para o aperfeiçoamento do direito material. (GRINOVER et. al., 2015)

Cumpre esclarecer que todos os pontos tratados até aqui devem ser entendidos como requisitos cumulativos para efetivação do direito ao acesso à justiça, visto que caso utilizados individualmente não teriam efeito algum no tocante à celeridade processual, otimização da resolução de conflitos e ao devido acesso à justiça em si.

Portanto, neste sentido, chega-se ao ponto principal do presente trabalho, ou seja, a adequação dos meios de resolução de conflito para a busca da pacificação social e sua efetivação no Código de Processo Civil de 2015, como veremos adiante. 


\subsection{A adequação dos meios de solução de conflito para se alcançar a pacificação social e sua efetivação no CPC de 2015}

Diante de tudo que foi narrado até o presente momento, podemos dizer que a "interpretação e aplicação do direito sofreram profundas transformações a partir da metade do século XX, principalmente de 1988 para cá, com a vigência da Constituição Federal e da supremacia dos direitos fundamentais e da visão social do direito" (FILHO, 2018, p. 200).

Tem-se assim, que a finalidade do processo já não é mais a mesma, o processo deixou de ser "mero instrumento para dizer o direito [...] e sim para garantir a tutela desses direitos, preventiva e repressivamente, diante de um acesso à justiça efetiva, justa, eficiente e adequada" (FILHO, 2018, p. 200).

Filho (2018, p. 201) explica que o processo possui três finalidades, sendo elas: assegurar a aplicação das normas, fazer incidir a lei sobre o caso concreto de forma justa e promover a pacificação social, com base nisso passamos a analisar o aspecto social do processo, que é o foco do presente trabalho.

Deste modo, "quando se fala em escopo social do sistema processual, tem-se a sua análise mediante a função da jurisdição e do processo dentro da sociedade, à vista da resolução de conflitos e tutela adequada dos direitos" (FILHO, 2018, p. 202).

Isso porque "constituem inevitáveis realidades as insatisfações que afligem as pessoas, as quais são estados psíquicos capazes de comprometer sua felicidade pessoal e trazem em si uma perigosa tendência expansiva" (DINAMARCO, 2016, v. 1, p. 220), essas insatisfações são os precursores dos conflitos, os quais devem ser sanados para que não se crie uma instabilidade social.

Ignorar as insatisfações pessoais importaria criar clima para possíveis explosões generalizadas de violência e de contaminação do grupo, cuja unidade acabaria por ficar comprometida. Como vem sendo dito, a litigiosidade contida é perigoso fator de infelicidade pessoal e desagregação social [...] e por isso constitui missão e dever do Estado a eliminação desses estados de insatisfação. (DINAMARCO, 2016, v. 1, p. 221)

Assim o escopo social do processo é promover a pacificação, "pacificar pessoas mediante a eliminação de conflitos com justiça é, em última análise, a razão mais profunda pela qual o processo existe e se legitima na sociedade" (DINAMARCO, 2016, v. 1, p. 221).

A pacificação deve ser então o objetivo de todo o meio se solução de conflitos como assevera Tartuce (2016, p. 226) ao dizer que "pacificar com justiça 
é a finalidade almejada por todo método idôneo de composição de controvérsias".

Tendo, pois, em vista que a função social do sistema processual é restabelecer a paz social com justiça, devese considerar que tanto os meios heterecompositivos arbitragem e o processo em si-quanto os autocompositivos - conciliação e mediação - têm por múnus atender essa finalidade. (FILHO, 2018, p. 203)

No entanto, a questão resulta do fato que "é manifestamente impossível satisfazer a todos - e a própria estrutura dialética dos conflitos mostra que a plena satisfação de um dos sujeitos implica contrariedade ao outro" (DINAMARCO, 2016, v. 1, p. 221).

Sendo que aqui reside a complexidade, pois a pacificação não se trata de uma "tarefa simples; por envolver o alcance de um estado de espírito humano, pacificar abrange aspectos não apenas jurídicos, mas sobretudo psicológicos e sociológicos" (TARTUCE, 2016, p. 226).

Assim, tendo em vista que "o tratamento dos conflitos pela via jurisdicional é pautado pela disputa acirrada, na qual as controvérsias hão de ser, no final, definidas no sistema de vencedores e vencidos" (TARTUCE, 2016, p. 82), ou seja, onde um sai ganhando e o outro perdendo.

Deste modo, sempre haverá alguém que irá sair insatisfeito da demanda, pondo fim a apenas uma parte do conflito sem, contudo pacificar a situação por completo, o que Tartuce (2016, p. 82) classifica como "o fenômeno da litigiosidade remanescente, persistindo certa sorte de controvérsia entre as partes após o fim de um processo porque certos aspectos não foram tratados adequadamente".

Neste ponto se legitima o emprego dos meios consensuais de solução de conflitos, pois "no modelo consensual, busca-se o 'ganha-ganha', de modo que os envolvidos sejam aptos a se compor e alcançar uma situação mas favorável em relação aos seus interesses, por intermédio de conversações e debates" (TARTUCE, 2016, p. 85).

Não há assim, um vencedor e um vencido, a solução para a situação é dada pelas próprias partes, dessa forma se alcança a pacificação real, ou seja, "a paz jurídica, social e psicológica" (FILHO, 2018, p. 204).

No entanto o enfoque da questão está em como alcançar a pacificação social efetiva, ou seja, a aceitação das soluções propostas, não só nos "meios autocompositivos - em que isso ocorre mais facilmente - quanto nas formas heterocompositivas - ainda que arraigado o sistema de ganha-perde com a insatisfação do vencido" (FILHO, 2018, p. 206), para que assim haja uma pacificação jurídica e psicológica. 
Ao examinar tal tema, Filho (2018, p. 206) explica que "o ponto principal da questão em análise é exatamente a aceitação, aqui compreendida como concordar - jurídica e psicologicamente - com a situação posta, seja no acordo, seja na decisão".

No campo jurídico a aceitação ocorre "com a formulação do acordo em caráter irrevogável, ou trânsito em julgado da decisão, ou ainda pelo cumprimento do teor do acordo ou da sentença judicial ou arbitral" (FILHO, 2018, p. 206).

Contudo, a aceitação psicológica é mais complexa, "porque traz o sentimento de perda para a pessoa, o que trabalha emoções, como frustração, irresignação e o descontentamento, ainda que de forma inconsciente, e que geram a insatisfação" (FILHO, 2018, p. 206).

Alguns autores explicam que essa aceitação vem a partir da maturidade pessoal, e "Esse alcance da maturidade da pessoa está intimamente ligado à aceitação dos fatos da vida, das perdas inclusive" (FILHO, 2018, p. 208), e para tanto se baseiam no modelo da psiquiatra suíça Kübler-Ross, as cinco fases da perda: negação, raiva, depressão, barganha e aceitação.

Tal método explica como as pessoas lidam com a perda, sendo passível a aplicação deste método no campo jurídico. Tartuce (2016, p. 228), ao dissertar sobre o tema, explica que "tais estágios nem sempre ocorrem nessa ordem nem precisam ser todos experimentados, mas a pessoa sempre passará por pelo menos dois deles".

Um ponto relevante a se destacar é em relação ao tempo, a duração desse processo, "o período entre a negação e aceitação da perda pode ser curto ou extremamente longo - às vezes nunca chegar" (FILHO, 2018, p. 211). Assim, nesse sentido, "quanto mais demorado o tempo de aceitação, mais dolorosa a situação torna-se para a pessoa" (FILHO, 2018, p. 211).

No entanto, o presente trabalho dará enfoque à fase da aceitação. "A aceitação configura o estágio de paz interna da pessoa" (FILHO, 2018, p. 211), "é o estágio em que efetivamente a pessoa tem condições de seguir em adiante; a partir de tal consciência, poderá buscar nova configuração para a sua situação" (TARTUCE, 2016, p. 229).

Ante a isso, a pacificação social será alcançada quando o indivíduo "diante da sua maturidade, compreender a perda como um fato da vida e que sua aceitação é necessária para estabelecer a paz interna e social" (FILHO, 2018, p. 211).

Deste modo, "ao se passar pelos cincos estágios do modelo proposto, é possível às partes litigantes, dentro da maturidade de cada um, aceitarem a perda, por vezes inevitável e, assim, proporcionarem a pacificação do conflito, tanto jurídico, quando social e psicológico" (FILHO, 2018, p. 211).

Como já mencionado nos modelos autocompositivos, tais objetivos são 
mais fáceis de atingir, uma vez que "não existe, ao menos em tese, um sentimento de perda" (FILHO, 2018, p. 211), pois são as próprias partes envolvidas que colocam fim a controvérsia, há o restabelecimento do diálogo.

Conclui-se assim que a "conciliação e mediação, quando bem trabalhada, com restabelecimento do diálogo e a compreensão das origens do conflito, retiram o caráter da perda, o que leva a uma aceitação rápida da solução apresentada" (FILHO, 2018, p.211).

É possível visualizar tal entendimento também na arbitragem mesmo que de uma forma reduzida, porque independente da resolução ser imposta por um terceiro/arbitro, a escolha deste é feita pelas partes em conflito de forma voluntária, ou seja, houve manifestação de vontade das partes na solução, tornando-se mais fácil aceitação da decisão.

Mesmo dentro do processo judicial é possível visualizar a pacificação, uma vez que "apesar de contrariado, o litigante vencido tende a aceitar a solução de seus conflitos com sofrimento menor que o decorrente das instabilidades inerentes à indefinição" (DINAMARCO, 2001, v. 1, 221), e como já estudado as decisões devem primar pela efetividade, justiça, eficiência e adequação.

Assim com a maturidade pessoal do indivíduo, aceitando o processo de perda, com base em uma decisão justa, a parte vencida com tempo, aceitará a decisão imposta pelo Estado-Juiz, gerando assim a pacificação no campo jurídico, bem como no psicológico.

Deste modo a legislação brasileira, precisa estar em consonância com essas primícias, para que haja de fato a efetivação da pacificação social, ou seja, para que se cumpra a função social do processo. Neste sentindo analisaremos a efetivação da pacificação social no Código de Processo Civil de 2015, os meios que são empregados para alcançar tal façanha.

Sendo quatro pontos que se destacam no Código de Processo Civil de 2015, "como instrumentos de pacificação social: a) a boa-fé objetiva; b) a cooperação c) modernização do contraditório; e d) a adequação dos meios de resolução de conflitos" (FILHO, 2018, p. 213).

O Código de Processo Civil traz como base o princípio da "boa-fé objetiva nas relações processuais como a finalidade de alcançar uma solução de conflito plasmada no acesso à justiça efetiva, justa, eficiente e adequada" (FILHO, 2018, p. 213).

Tanto é que está previsto de forma expressa no art. $5^{\circ}$ do Codex, "aquele que de qualquer forma participa do processo deve comportar-se de acordo com a boa-fé" (BRASIL, 2015), assim cabe a todos, inclusive aos magistrados, serventuários, analistas, advogados, as partes litigantes, e a todos que de alguma forma participem do processo, agir com boa-fé, primando pelo bom andamento do processo. 
Desta forma tem-se que a boa-fé objetiva, trata-se de um padrão de conduta plasmado na lealdade daqueles que participam do processo (FILHO, 2018, p. 214). Assim, a boa-fé objetiva é imprescindível na "construção da pacificação social, porquanto não se tem uma solução de conflito efetiva, justa, eficiente e adequada sem que todos os participantes do processo atuem com honradez, probidade, respeito mútuo e cooperação" (FILHO, 2018, p. 216).

O segundo ponto que se destaca é a cooperação, sendo que o próprio significado da palavra cooperação explica o que é este princípio. Desta forma a cooperação aqui se põe como o dever que todos os envolvidos no processo têm de cooperar uns com os outros para que se alcance o fim almejado pelo processo, ou seja, uma decisão efetiva, justa, eficiente e adequada.

Tal entendimento se extrai do próprio código que em seu art. $6^{\circ}$ preceitua que "todos os sujeitos do processo devem cooperar entre si para que se obtenha, em tempo razoável, decisão de mérito justa e efetiva" (BRASIL, 2015). Vale mencionar ainda que tal princípio está intimamente ligado ao anterior, uma vez que "traz como pressuposto a lealdade e respeito como regra de conduta a guiar todo o caminhar do processo e dos seus atos" (FILHO, 2018, p. 218).

Nessa ordem, sem temor de repetição, pode-se afirmar que um processo cooperativo almeja promover, essencialmente, a efetividade e justiça da prestação jurisdicional, impondo uma conduta judicial mais ativa, complementando um procedimento flexível adaptável às necessidades do caso para a resolução adequada de conflitos e sua pacificação. (FILHO, 2018, p. 219)

Diante do princípio da boa-fé e da cooperação se criou "uma nova forma de visualizar o contraditório, agora num modelo participativo e dialogado, também pilar da pacificação construída no Código de Processo de 2015" (FILHO, 2018, p. 219), sendo este o terceiro instrumento de pacificação.

O contraditório está previsto legalmente na Constituição Federal, inserido no art. $5^{\circ}$, inciso LV, possuindo garantia de direito fundamental, "aos litigantes, em processo judicial ou administrativo, e aos acusados em geral são assegurados o contraditório e ampla defesa, com os meios e recursos a ela inerentes" (BRASIL, 1988).

Trata-se de uma garantia de participação do indivíduo no processo, "garantia de influir (pressupondo o exercício de influência) antes do juiz proferir a decisão judicial" (FILHO, 2018, p. 220). No entanto não se limita apenas a participar, mas de "influir decisivamente nos destinos do processo. Há, pois, frise-se, o direito de se manifestar, de ser ouvido, mas, também, o de ter suas manifestações levadas em consideração" (FILHO, 2018, p. 220). 
Assim, frente a nova visão do processo, com base no princípio da boafé e da cooperação, tem-se que o contraditório "somente se considerará atendido [...] se propiciada às partes a participação real e efetiva na realização dos atos preparatórios da decisão judicial" (FILHO, 2018, p. 220). Deste modo é vedado "a prolação de decisões com surpresa para as partes" (FILHO, 2018, p. 220).

Neste sentido, o próprio Código já estabelece como regra em seu art. $10^{\circ}$ que "o juiz não pode decidir, em grau algum de jurisdição, com base em fundamento a respeito do qual não se tenha dado às partes oportunidade de se manifestar, ainda que se trate de matéria sobre a qual deva decidir de ofício" (BRASIL, 2015).

Com base nessas informações podemos dizer que o objetivo é dar maior efetividade e celeridade ao processo, pois "com uma decisão bem fundamentada por questões sobre as quais todas as partes tiveram a oportunidade de se manifestar, ainda que não fizessem, propiciam decisões com maior grau de efetividade, evitando-se, talvez, a interposição de recursos desnecessários" (FILHO, 2018, p. 221).

Neste ponto, chegamos ao quarto ponto de efetivação da pacificação social, no Código de Processo Civil de 2015, que é a adequação dos meios de solução de conflitos, sendo este um dos pontos mais relevantes, se não o mais.

Como já mencionado anteriormente, o homem é um ser social e possui a necessidade de viver em sociedade, por esse motivo, tem-se que é uma característica intrínseca do homem o surgimento de conflitos, diante das divergências de ideias, bem como, se pode dizer que no Brasil desenvolveu-se uma cultura de passar para o estado a responsabilidade de resolver tais conflitos. E, como resultado dessa cultura tem-se o que chamamos de crise estatal caracterizada pela superlotação do poder judiciário.

Em reposta a crise, como tentativa de solucionar a questão, "vieram as reformas e a procura por alternativas e ideias a fim de atender a demanda social em constante conflito" (FILHO, 2018, p. 223). Sendo que o foco, a prioridade era "à redução de processos e a supressão e simplificação de atos processuais" (CALMON, 2015, p. 42).

Uma das principais medidas tomadas foi estimular o uso de meios alternativos de solução de conflito, sendo que o Conselho Nacional de Justiça - CNJ teve um papel muito importante nessa função. Porém, o objetivo que se tinha era equivocado "Isso porque, em um primeiro momento, visava resolver o acúmulo de processos, sem se preocupar com efetividade, justiça eficiência e adequação da solução" (FILHO, 2018, p. 223).

Um exemplo disso são as metas estabelecidas, sempre em vista de se diminuir o volume de processos 
pendentes, principalmente. Outro exemplo que também ganha destaque é a imposição da Semana Nacional da Conciliação, iniciada no ano de 2006 - com o Dia Nacional da Conciliação - e que também tinha por objetivo - ainda que não declarado explicitamente - solucionar a crise numerária do Judiciário. (FILHO, 2018, p. 223)

Revelando-se nesse ponto um grande problema, pois "tentar a solução da crise por intermédio de 'meios alternativos' de solução de conflitos. Trata-se de premissa falsa e que não retrata a ideia principal da questão" (FILHO, 2018, p. 223).

Nesse sentindo, há uma necessidade de mudar a forma de visualização dos meios de solução de conflitos, abandonar a visão de evasão numérica, e passar para uma visão de efetivação de direitos, de forma eficiente, justa, efetiva e adequada. Assim, é imprescindível "aplicar medidas de aperfeiçoamento da atividade jurisdicional, que irão dar todo o sustentáculo para os meios de resolução de conflitos promoverem a pacificação social" (FILHO, 2018, p. 224).

Ante a isso, a resposta a crise tem que partir do princípio de que "os conflitos precisam ter uma solução à luz do acesso à justiça efetiva, justa, eficiente e adequada dentro da visão do Estado Constitucional de Direito, plasmado na garantia fundamental da pessoa ao processo justo como instrumento da tutela dos direitos e de pacificação social" (FILHO, 2018, p. 224).

Significa dizer que os meios de solução de conflitos existentes, sejam os autocompositivos - pela conciliação ou mediação -, sejam os heterocompositivos - pela arbitragem ou processo em específico -, devem ser considerados pela seguinte premissa: o meio deve ser adequado à solução do conflito posto para a promoção da pacificação social. (FILHO, 2018, p. 224)

E para alcançar essa premissa, de que o meio utilizado para prestar a solução deve ser adequado a produzir a pacificação, Filho aponta dois aspectos, sendo o "primeiro deles é conhecer o conflito, suas origens e tipologia" (2018, p. 225), e o "segundo aspecto refere-se à estrutura do Judiciário e da lei processual" (2018, p. 227).

O primeiro aspecto estipula que conhecer o conflito "na sua essência - a natureza humana, suas necessidades e compreender como a desavença se originou, no plano sociológico inclusive -, é imprescindível para uma solução adequada, dentro da visão pacificadora do processo" (FILHO, 2018, p. 225).

Assim é necessário compreende com que espécie de conflito se está 
lidando, para que a resposta atribuída a este seja adequada, promovendo os fins que se espera, ou seja, um acesso à justiça efetivo, justo, eficiente e adequado, bem como a efetivação da pacificação social.

Essa análise da espécie do conflito deve levar em conta alguns fatores como o conflito propriamente dito, as partes envolvidas, o ambiente na qual estão inseridas socialmente, experiências semelhantes e a urgência da situação (FILHO, 2018, p. 225-226).

Esses fatores ajudaram a classificar o conflito e assim qual o meio adequado para solucioná-lo. Vale esclarecer que os conflitos não são idênticos, por se tratar de pessoas que como já estudado, são seres diferentes. Assim cada situação será única, podendo até ter pontos semelhantes com outras, mas ainda assim únicas.

Nessa linha de contada, o mesmo meio de solução para um conflito de natureza familiar pode não ser o mais adequado para um conflito de natureza consumerista, ou de responsabilidade civil. O meio mais adequado para um conflito individual não é, do mesmo modo, mais adequado num conflito coletivo. (FILHO, 2018, p. 226-227)

Deste modo, ante aos diversos métodos de solução de conflitos que se tem, como a "conciliação, mediação, arbitragem ou o processo -, deve-se considerar aquele que é mais adequado para solução do conflito, de acordo com a sua natureza e diante do caso concreto posto" (FILHO, 2018, p. 227).

$\mathrm{O}$ segundo ponto diz respeito à estrutura do judiciário, bem como a estrutura da lei processual. No campo da estruturação tem-se que é necessário o "aperfeiçoamento da justiça tradicional" (FILHO, 2018, p. 227). Nesse sentindo Calmon (2015, p. 44) explica que "profundas alterações têm sido adotadas no processo e no aparelho judicial brasileiro, visando à efetividade do processo e desmitificando cânones antigos, como o da tripartição do processo (conhecimento, execução e cautelar)".

Sendo que uma das principais alterações a se destacar, foi a criação de uma política de tratamento adequado dos conflitos, introduzida com a Resolução n. 125 datada de 29 de novembro de 2010. É possível visualizar desde as motivações da resolução a preocupação com o tratamento adequado dos conflitos, como acesso à ordem jurídica justa e a soluções efetivas.

Cabe ao Judiciário estabelecer política pública de tratamento adequado dos problemas jurídicos e dos conflitos de interesses, que ocorrem em larga e crescente escala na sociedade, de forma a organizar, em âmbito 
nacional, não somente os serviços prestados nos processos judiciais, como também os que possam sê-lo mediante outros mecanismos de solução de conflitos, em especial dos consensuais, como a mediação e a conciliação. (BRASIL, 2010)

Tal entendimento se reforça no corpo da resolução, como em seu art. $1^{\text {o }}$ "Fica instituída a Política Judiciária Nacional de tratamento dos conflitos de interesses, tendente a assegurar a todos o direito à solução dos conflitos por meios adequados à sua natureza e peculiaridade" (BRASIL, 2010).

Fica demonstrado que a intenção da Resolução foi aprimorar o tratamento dos conflitos de forma adequada, bem como incentivou a criação de programas de autocomposição e criou os Centros Judiciários de Solução de Conflitos e Cidadania (CEJUSC), propagou a ideia da cultura do diálogo e da pacificação social (FILHO, 2018, p. 229).

A segunda alteração importante foi a promulgação do Código de Processo Civil de 2015. Como já citado aqui inúmeras vezes, este código é regido por princípios constitucionais e possui um caráter preventivo, trouxe "a ideia de aprimoramento da solução do conflito, diante de uma visão de adequação e promoção da pacificação social" (FILHO, 2018, p. 229).

O Código de Processo Civil também se fundamenta em um sistema chamado multi-door dispute resolution ou Justiça Multiportas, que teve início nos Estados Unidos com as "ideia de Frank Sander, professor da universidade de Havard, desenvolvidas na The Pound Conference: perspectives on justice in thee future, que correu entre os dias 7 e 9 de abril de 1976 em St. Paul, Minessota" (FILHO, 2018, p. 231).

Tal sistema, é "a pedra inicial da busca pelos meios adequados na solução de conflitos" (FILHO, 2018, p. 231). Sander desenvolveu a ideia de que é necessário estudar as características dos meios de solução de conflito há disposição, e como podem ser utilizados diante das infinidades de conflitos existentes na sociedade (FILHO, 2018, p. 232).

Defende também "a flexibilidade e a diversidade de meios de resolução de conflitos na justiça estatal, com tipos específicos de casos sendo atribuídos a diferentes mecanismos (ou a combinação desses) para a melhor solução" (FILHO, 2018, p. 232-233).

Assim quando o Código de Processo Civil traz em seu corpo (art. $3^{\circ}, \S \S$ $1^{\circ}, 2^{\circ}$ e $3^{\circ}$ ) a previsão de utilização dos meios autocompositivos e a arbitragem. "Não se trata de meios alternativos. O Código em si não trata a arbitragem, conciliação e mediação dessa forma, o que está correto" (FILHO, 2018, p. 230), pois se trata de meios adequados de promover a solução do conflito e alcançar a pacificação social. 
Outro ponto relevante do Código de Processo Civil de 2015 é a adaptabilidade do procedimento, ou seja, o Código traz a possibilidade de flexibilizar os atos processuais, rompendo como o sistema rígido que se tinha no Código de 1973 que adotava "exclusivamente a regra da tipicidade do procedimento" (FILHO, 2018, p. 236).

É possível visualizar essa flexibilização através do art.139, VI, o qual atribui poder ao Juiz de "dilatar os prazos processuais e alterar a ordem de produção dos meios de prova, adequando-os às necessidades do conflito de modo a conferir maior efetividade à tutela do direito" (BRASIL, 2015).

Outro ponto notório de flexibilização do procedimento, é a possibilidade de inversão do ônus da prova, inserida no art. $373, \S 1^{\circ}$. Sendo que tal possibilidade já era prevista no Código de Defesa do Consumidor.

\begin{abstract}
Art. 373. [...]
$\S 1^{\circ}$ Nos casos previstos em lei ou diante de peculiaridades da causa relacionadas à impossibilidade ou à excessiva dificuldade de cumprir o encargo nos termos do caput ou à maior facilidade de obtenção da prova do fato contrário, poderá o juiz atribuir o ônus da prova de modo diverso, desde que o faça por decisão fundamentada, caso em que deverá dar à parte a oportunidade de se desincumbir do ônus que lhe foi atribuído. (BRASIL, 2015)
\end{abstract}

Desta forma, em linhas conclusivas de raciocínio, entende-se que "acesso à justiça adequada pressupõe uma tutela adequada do conflito, seja pelo meio de solução empregado, seja pela adaptabilidade do procedimento a ser adotado" (FILHO, 2018, p. 239), e dessa forma promover decisões efetivas, justas, eficientes e adequadas, e cumprir o escopo do maior do processo, ou seja, promover a pacificação social.

Outro ponto necessário ser abordado é a necessidade de mudança de paradigma da sociedade, ou seja, é necessário que haja a quebra do padrão existente. "É preciso, pois, deixar a cultura da litigiosidade, arraigada na sociedade brasileira, para uma nova forma de pensamento, plasmada na cultura da pacificação" (FILHO, 2018, p. 241).

Tocantemente no aspecto legislativo, ficou evidenciado que o Código de Processo Civil de 2015 presenteou o ordenamento pátrio com uma ótica totalmente diferente da que se tinha com o Código de Buzaid e em suas reformas. Como dito, trouxe para a legislação que regimenta os ritos processuais a busca pela solução mais adequada do litígio com a finalidade de eliminar os conflitos sociais e 
promover sua pacificação social. (FILHO, 2018, p. 241)

Sendo que a dúvida persistente em tal tema "é como implementar essa cultura da pacificação em uma sociedade que está habituada a levar ao Judiciário seu conflito em busca de uma solução soberana por ela emanada - leia-se sentença” (FILHO, 2018, p. 241), ou seja, como alterar tal cultura.

Essa mudança de mentalidade deverá acontecer por meio de uma conscientização, pois o "Código de Processo Civil de 2015 entra como protagonista, justamente pela mudança de visão do processo e na quebra do paradigma da cultura da litigiosidade" (FILHO, 2018, p. 241), neste sentindo há a necessidade "de uma mudança de postura da própria sociedade" (FILHO, 2018, p. 242).

Nessa trajetória relacional, a simples mudança legislativa não importará qualquer transformação no quadro atual se não acompanhada da quebra do paradigma social que se vive no Brasil. A modificação na forma de pensar da sociedade em geral, desde o cidadão comum até os operadores do direito e responsáveis pela administração pública em geral e da justiça, principalmente, é imprescindível. (FILHO, 2018, p. 242)

Assim, as ideias e os métodos trazidos pelo Código de Processo Civil só terão efetividade, ou seja, só alcançará a adequação dos meios de solução de conflitos e a pacificação social, quando houver aceitação por parte da sociedade desse novo modelo.

Pode-se dizer que isso só ocorrerá por meio da educação dos indivíduos, pelo abandono do modelo arcaico que se tinha. E essa mudança de mentalidade deve partir da sociedade jurídica, dos operadores do direito em todos os ramos, pois é função destes orientar e conduzir os cidadãos á solução de seus conflitos.

Deste modo conclui-se que só a implementação de medidas adequadas de solução de conflitos, sem, contudo, haver a mudança de paradigma da sociedade de nada adiantaria. Dessa forma é preciso entender que o processo em si, não é o único meio hábil de dar uma resposta adequada ao conflito, que se deve levar em consideração a particularidade de cada caso e a partir disso buscar o meio adequado de solução, para assim promover um acesso à justiça eficiente, justa, eficaz e adequada e alcançar a pacificação social. 


\section{CONSIDERAÇÕES FINAIS}

Ante a tudo o que foi exposto, da pesquisa realizada, conclui-se que há a necessidade de adequação dos meios de solução dos conflitos não como uma forma de desafogar o poder judiciário, mas sim de dar efetividade ao que o Estado Constitucional de Direito espera, ou seja, promover um acesso à justiça efetiva, justa, eficiente e adequada.

Sendo que o Código de Processo Civil possui um papel extremamente importante nessa missão, pois este tenta romper com a cultura litigiosa, trazendo em seu bojo princípios e técnicas, para melhor resolver os conflitos respeitando a particularidade de cada caso, adequando o procedimento ao caso concreto.

E deste modo também é preciso mudar o paradigma social, porque de nada adiantaria introduzir tais alterações, se a sociedade não as aceitarem. Assim é preciso abandonar a ideia de que a única forma adequada de pôr fim a controvérsia é até através de um processo litigioso.

Neste ponto, é necessário que haja uma conscientização da sociedade, e em especial dos operadores do direito, desde acadêmicos de direito a advogados, promotores, procuradores, analistas, magistrados, ou seja, de todos aqueles que manejam o direito, pois são estes os responsáveis por conduzir os indivíduos à melhor solução dos seus conflitos.

Assim a adequação dos meios de solução de conflitos, virá por meio da mudança de paradigma da sociedade, aceitando o novo modelo processual, trazida pelo Código de Processo Civil de 2015, através também, da implementação de políticas públicas, que estimulem a utilização dos meios consensuais de solução de conflitos, não como meios alternativos, mas sim como meios adequados de solução de conflitos, respeitando a particularidade de cada caso, na suas formas extraprocessual, endoprocessual, e também da arbitragem.

E principalmente, através da educação, pois sem essa os outros métodos não serão alcançados. Quando se fala da educação engloba todas as pessoas, desde as suas primeiras relações (como a briga por um brinquedo na infância), até as suas relações mais complexas. É preciso criar uma cultura da pacificação, ou seja, ensinar os indivíduos a pacificar, a entrar em consenso, e essa cultura tem que ser o norte, a direção da sociedade, para assim promover a tão esperada pacificação social.

\section{REFERENCIAS}

BRASIL. Conselho Nacional de Justiça - CNJ. (2017). Justiça em Números 2017: ano-base 2016. Brasília: CNJ, 2017. 
. Conselho Nacional de Justiça - CNJ. (2018). Justiça em Números 2018: ano-base 2017. Brasília: CNJ, 2018.

. Conselho Nacional de Justiça - CNJ. Resolução n. 125, de 29 de novembro de 2010. Dispõe sobre a Política Judiciária Nacional e tratamento adequado dos conflitos de interesses no âmbito do Poder Judiciário e dá outras providências. Disponível em: http://www.cnj.jus.br/busca-atosadm?documento=2579. Acesso em: 30 mai. 2019.

\section{. Constituição (1988). Constituição da República Federativa do}

Brasil: promulgada em 5 de outubro de 1988. Disponível em: http://www. planalto.gov.br/ccivil_03/constituicao/constituicao.htm. Acesso em: 30 mai. 2019.

. Lei Federal n. 13.105, de 16 de março de 2015. Código de Processo Civil. Diário Oficial da República Federativa do Brasil, Brasília, 17 de mar. 2015.

CALMON, P. Fundamentos da Mediação e da Conciliação. 3. ed. Brasília: Gazeta Jurídica, 2015.

CÂMARA, A. Mediação na Res. 125 do CNJ e no projeto de Código de PROCESSO Civil. In: MENDES, A. G de C.; WAMBIER, T. A. A. (orgs.). Processo em perspectiva: jornadas brasileiras de direito processual. São Paulo: RT, 2014.

CAPPELLETTI, M.; GARTH, B. Acesso à Justiça. Porto Alegre: Sergio Antonio Fabris Editor, 1988.

DINAMARCO, C. R. Instituições de Direito Processual Civil. São Paulo: Malheiros, 2016. v. 1.

FILHO, G. F. M. Os Direitos Fundamentais, a Pacificação dos Conflitos Sociais e o Código de Processo Civil: o Novo Paradigma do Processo Civil em Vista do Acesso à Justiça Efetiva, Justa, Eficiente e Adequada. Campo Grande: Contemplar, 2018.

GRINOVER, A. P. et. al. Conferência de Soul 2014 Constituição e Processo - Acesso efetivo à justiça: o direito de acesso à justiça e responsabilidade públicas. Revistas de processo. São Paulo, Revista dos Tribunais, v. 250/2015, dez. 2015. 
MONDIN, B. O homem, quem é ele?: Elementos de antropologia filosófica. São Paulo: Paulus, 1980.

TARTUCE, F. Mediação nos conflitos civis. 3. ed. Rio de Janeiro: Forense; São Paulo: Método: 2016. 